\title{
RECENT IMPROVEMENTS IN BCG VACCINE PRODUCTION
}

\author{
J. UNGAR \\ Glaxo Laboratories Ltd., Greenford, Middlesex
}

WoRk has been directed recently towards the development of a freeze-dried BCG vaccine with the property of heat stability in order to provide a vaccine which will retain its potency if exposed for short periods to the high environmental temperatures experienced in tropical countries.

Numerous attempts have been made to improve the heat stability of freeze-dried BCG vaccine. Earlier attempts have been concentrated on the menstruum in which the organisms are freeze dried since this has usually been regarded as the most important factor affecting loss of viability during both freeze drying and subsequent storage.

In our laboratory the actions of many different media for freeze-drying BCG have been investigated including that of sodium glutamate (Muggleton, 1960) but under our conditions and with our substrain of BCG no outstanding improvement in survival on storage at elevated temperatures was obtained.

We therefore decided to investigate the possibility that the culture medium in which the BCG was grown might have some influence on the stability of the subsequently prepared vaccine.

Heap and Cadness (1924) have noticed that the addition of glucose to the peptone-water medium slowed down the growth of Salm. typhimurium after a few days. Dubos and Fenner (1950) searching for a medium for the optimal growth of BCG, found that a striking decrease in viability of the culture occurred on prolonged incubation if $0.5 \%$ glycerol were included in the medium. Recently Scott (1960) has shown that the cause of instability of vaccines at higher temperatures is due to the presence of aldehydes within the cells before freeze drying formed by breakdown of glycerol. Carbonyl groups of these substances react with amino-acids of cell proteins to give rise to toxic 'browning reactions' compounds of the cells.

It was decided to produce a medium without glycerol for the growth of BCG.

This aim has been achieved and we are now producing BCG vaccine with a considerably increased stability to heat. The new vaccine is not only more resistant to elevated temperatures, it is also more resistant to freeze drying with the result that a smaller precentage of organisms are lost during the freeze-drying process.

A keeping trial was performed in order to establish the degree of heat stability of the net vaccine.

\section{Percutaneous BCG Vaccine}

A freeze-dried BCG vaccine suitable for pero cutaneous vaccination has been developed em ploying the glycerol-free medium for growth of the BCG organisms. The growth from glycerolo free medium, being more stable towards freez drying than that from Sauton's medium, has mad\&o it possible to obtain the high viable count $(50$ t 8 $25^{\circ} \times 10^{6}$ per ampoule) necessary for effectivo BCG vaccination by the percutaneous route with $\vec{a}$ relatively much smaller weight of BCG organisms Thus a vaccine with an acceptable viable count now prepared from glycerol-free medium b filling a moist weight of $3.0 \mathrm{mg}$. BCG as opposed to the $20 \mathrm{mg}$. necessary when the Sauton gropth was employed.

Even $3 \mathrm{mg}$. moist weight/ampoule requires employment of 200 'mould culture' flasks eace containing $100 \mathrm{ml}$. of medium for the preparatio $\overline{0}$ of one batch of 2,000 ampoules of percutaneous BCG vaccine. It has been demonstrated b\% Dr. M. Griffiths by trials in children that th number of viable units in a percutaneous BCG vaccine determines its efficacy and not the total bacterial mass present. Since the percutaneou vaccine is not in a unicellular state but consists of aggregates of BCG bacilli of varying size, seemed logical to endeavour to prepare vaccines i a more highly divided state and to then establist by clinical trial whether such vaccines, with acceptable viable counts but lower moist weights were as effective for percutaneous BCG vaccinas tion as are the existing batches. $\mathrm{We}$ are act cordingly employing a sterile mixing apparatus (Silverson stirrer) to break up aggregates of BCF organisms, during preparation of experimental batches of vaccine in order to test this hypothesis Preliminary work has indicated that the method employed yields a suitable viable count in the fing freeze-dried product from a fill of $1.0 \mathrm{mg}$./ampoute instead of $3.0 \mathrm{mg}$./ampoule. Further work is i progress to prove that this is repeatable under production conditions. Experimental batches are in course of preparation and will be submitted for clinical evaluation shortly. 
Effect of Storage at $37^{\circ} \mathrm{C}$. And $42^{\circ} \mathrm{C}$. On Viable Count

\begin{tabular}{|c|c|c|c|c|c|c|c|}
\hline \multirow{2}{*}{\multicolumn{2}{|c|}{ Batch }} & \multirow{2}{*}{$\begin{array}{l}\text { Storage } \\
\text { Temp. }\end{array}$} & \multicolumn{4}{|c|}{ Period of Storage (months) } & \multirow{2}{*}{$\begin{array}{l}\text { Fall in viability } \\
\text { in I Month }\end{array}$} \\
\hline & & & $\circ$ & I & 2 & 4 & \\
\hline $\begin{array}{l}489 \mathrm{~A} \\
\text { Glycerol-free medium }\end{array}$ & $\ldots$ & $\begin{array}{r}4^{\circ} \mathrm{C} . \\
37^{\circ} \mathrm{C} . \\
42^{\circ} \mathrm{C} .\end{array}$ & I 2.8 & $\begin{array}{c}18.3 \\
6.4 \\
4.12\end{array}$ & $\begin{array}{c}\text { I } 1.7 \\
2.9 \\
0.36\end{array}$ & $\begin{array}{r}16.75 \\
\text { I.94 } \\
0.16\end{array}$ & $\begin{array}{c}\circ \\
50 \% \\
68 \%\end{array}$ \\
\hline $\begin{array}{l}428 \\
\text { Glycerol-free medium } .\end{array}$ & $\cdots$ & $\begin{array}{r}4^{\circ} \mathrm{C} . \\
37^{\circ} \mathrm{C} . \\
42^{\circ} \mathrm{C} .\end{array}$ & 15.4 & $\begin{array}{r}17.0 \\
7.5 \\
4.8\end{array}$ & $\begin{array}{r}\text { I } 5.9 \\
5.2 \\
\text { I.4 }\end{array}$ & $\begin{array}{l}16.7 \\
1.46 \\
0.047\end{array}$ & $\begin{array}{c}0 \\
51 \% \\
69 \%\end{array}$ \\
\hline $\begin{array}{l}\text { Fio } \\
\text { Glycerol-free medium }\end{array}$ & $\cdots$ & $\begin{array}{r}4^{\circ} \mathrm{C} . \\
37^{\circ} \mathrm{C} . \\
42^{\circ} \mathrm{C} .\end{array}$ & 10.7 & $\begin{array}{l}\text { II.7 } \\
6.65 \\
5.0\end{array}$ & $\begin{array}{c}11.0 \\
2.57 \\
0.8\end{array}$ & $\begin{array}{l}\text { I5.I } \\
\text { I.I3 } \\
0.27\end{array}$ & $\begin{array}{l}\circ \\
38 \% \\
53 \%\end{array}$ \\
\hline $\begin{array}{l}5^{18 \mathrm{~A}} \\
\text { Sauton's medium }\end{array}$ & $\ldots$ & $\begin{array}{r}4^{\circ} \mathrm{C} . \\
37^{\circ} \mathrm{C} . \\
42^{\circ} \mathrm{C} .\end{array}$ & $7 \cdot 5$ & $\begin{array}{l}7.4 \\
0.73 \\
0.023\end{array}$ & $\begin{array}{l}7.0 \\
0.27 \\
0.005 \\
\end{array}$ & $\begin{array}{l}5.1 \\
0.011 \\
0 \\
\end{array}$ & $\begin{array}{l}\circ \\
90 \% \\
99.7 \% \\
\end{array}$ \\
\hline
\end{tabular}

\section{Isoniazid (INAH) Resistant BCG Vaccine}

The standard strain of BCG (strain 1077) originally derived from the Statenserum Institute in Copenhagen employed in this laboratory for the preparation of freeze-dried BCG vaccine is sensitive to $0.02 \mu \mathrm{g} . / \mathrm{ml}$. of isonicotinic acid hydrazide (INAH). The normal vaccine is therefore of little use for the vaccination of tubercular contacts who are being treated with INAH as a preventive measure.

A substrain of strain 1077 which is resistant to INAH has therefore been developed by serial passage in vitro in the presence of the drug. This strain 192 requires a minimal inhibitory concentration (MIC) of INAH of $25 \mu \mathrm{g} . / \mathrm{ml}$. and is therefore resistant to this antitubercular drug.

Before the development of the new glycerol-free medium, however, this strain 192 which (in common with all INAH-resistant mycobacterial strains) is catalase-negative and incapable of growth in Sauton's medium, even with catalase added, had to be grown in Dubos' liquid medium which contains bovine albumin (fraction V). The medium had to be thoroughly removed by washing the growth with distilled water but, nevertheless, the possibility of albumin remaining in the final vaccine with its attendant dangers had to be faced. It was found, however, that strain 192 grew with facility in the new glycerol-free medium and since this medium contains no undesirable protein it has since been employed in preference to Dubos' medium for the preparation of INAH-resistant BCG vaccine.

The Glaxo BCG Unit was extended in 1962 in order to meet the constantly rising demands for freeze-dried BCG vaccine, and among other improvements which were introduced at the time was the installation of a large shelf freezedrier. This unit, an L 20 by Edwards High Vacuum Ltd., is mounted with only its door opening into the sterile area, the plant being accommodated in a room outside in order that the drier may be serviced by engineers without interference with the integrity of the sterile area in which vaccine is manufactured.

This advanced freeze-drier automatically controls the freeze drying of a load of more than 6,000 ampoules of BCG vaccine by thermostatically controlling the heat input required to counterbalance the loss of heat vaporization from the drying product. The temperature of shelves, product and refrigerator-condenser which collects the water are recorded and it is now possible accurately to control the freeze-drying process and so obtain greater constancy in the final product.

Finally I would like to mention that a freezedried vaccine was also prepared for use by the oral route and more recently we have made a vaccine available for studies of non-specific immunity.

\section{REFERENCES}

Dubos, R. J., and Fenner, F. (1950): Production of BCG Vaccine in a Liquid Medium Containing tween 80 and a Soluble Fraction of Heated Human Serum, F. exp. Med., 9r, 26r, No. 3.

Heap, H., and CadNess, B. H. E. (I924): The Influence of Carbohydrates on Hydrogen Sulphide Production by Baccillus aertrycke (Mutton), $\mathcal{F}$. Hyg. (Lond), 23, 77.

Muggleton, P. W. (1960): Freeze-Drying of Bacteria with Special Reference to BCG in Recent Research in Freezing and Drying, edited by A. S. Parkes and A. Smith, p. 229. Oxford: Blackwell.

Scotr, W. J. (1960): A Mechanism Causing Death During Storage of Dried Micro-Organisms, Ibid., p. 188. 